\title{
Fish Processing Efficiency Ranking
}

\author{
Zane INDZERE ${ }^{*}$, Dagnija BLUMBERGA ${ }^{2}$ \\ ${ }^{1,2}$ Institute of Energy Systems and Environment, Riga Technical University, Azenes iela 12/1, Riga, \\ LV-1048, Latvia
}

\begin{abstract}
Fish as food has been widely used, and as its consumption is increasing, the efficiency of fish production companies needs to be increased as well. Fish production may consist of many processes, depending on the type of fish products they produce. Based on this, the increase in the efficiency of the whole company could be expensive, especially for small size companies, whose revenues per year are rather small. Therefore, to evaluate and understand which part of the company is the least efficient and needs to be improved first to have the highest increase in the efficiency of the company, the decision making method needs to be used for the evaluation. In this research, the method MULTIMOORA was chosen to evaluate the specific company's production efficiency. The results have shown that fish preliminary processing is the least efficient process for the chosen case study. Recommendations for improvement the efficiency of the least efficient stage have been developed, therefore improving the efficiency for the whole company.
\end{abstract}

Keywords - Canning; fish; multi-criteria decision making method; MULTIMOORA; processing; product; production

\section{INTRODUCTION}

Fish as a food has become one of the main food resources for human beings. Based on the available data on the Food and Agriculture Organization of the United Nations (FAO), it is stated that in 2016 the apparent consumption of fisheries and aquaculture products was $20.3 \mathrm{~kg}$ per capita per year. Moreover, the consumption of these products within last six years has increased by almost $9 \%$ (see Fig. 1) [1].

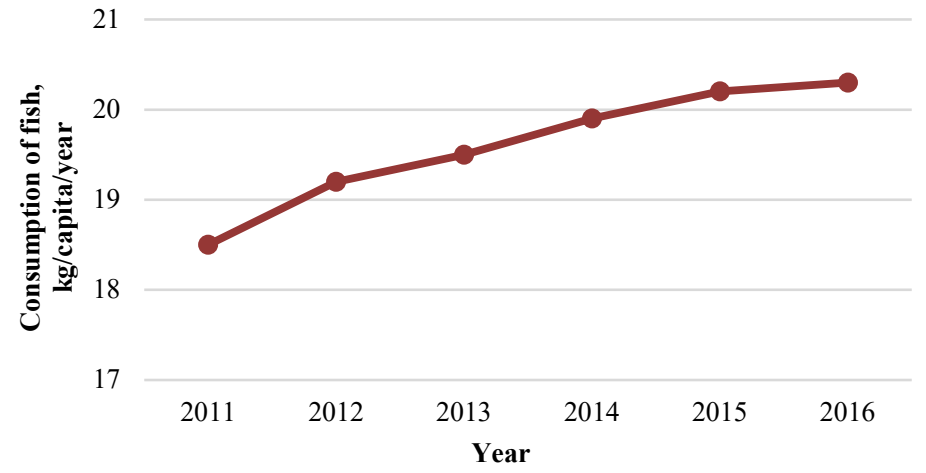

Fig. 1. Fish consumption per capita per year [1].

* Corresponding author.

E-mail address: zane.indzere@rtu.lv 
These numbers are even higher when the situation in Europe is shown. Some European countries consume way larger amount of fish than the average consumption mentioned by FAO, for example, the fish consumption in Portugal is $55.9 \mathrm{~kg} / \mathrm{capita} /$ year which is twice as more than the average consumption per capita; also citizens in Spain consumes high amount of fish - $45.2 \mathrm{~kg} /$ capita/year; in Latvia - $26.3 \mathrm{~kg} /$ capita/year in 2015 . Also, the average consumption of fish and aquaculture products is higher in Europe - $25.1 \mathrm{~kg} / \mathrm{capita} / \mathrm{year}$ [2]. Not only consumption, but also the fishing sector including fishing and fish processing is developed and has essential importance within the fishery industry - in European Union 5.3 million tonnes of fish have been caught in 2016 [3].

The increased consumption of fish and the growing number of people is leading to even higher amount of fish consumption in the future. This means that it will be necessary to increase the technological load in the fish processing companies to meet the needs of the growing population. These dynamic changes are pushing fish industry to increase the efficiency within the fish processing companies, therefore decreasing the negative impact on environment while maintaining their productivity [4]. However, fish catching and its harvesting are topics that still needs to be highly considered.

The improvements in the production processes are also important due to competiveness, and sustainability challenges that the industry is facing now. One of the sustainability challenges are created due to the fact that the fish production is a source for several environmental issues because of high energy consumption, use of high amount of water, therefore also creating great amount of wastewater, waste, as well as noise, and odour [5]. The environmental problems are caused from the various technologies and processes that are used in fish production stages, for example, smoking, frying, cooking, boiling and drying of fish consumes high amount of energy. The high amount of energy is also needed to freeze the fish and keep it frozen. Terehovics et al. researched how freezing processes in the fish production could be improved. One of the main conclusion was that the specific energy consumption needed to freeze the fish was lower than that needed to maintain their frozen state [6]. This could lead to some suggestions for improvement in the efficiency of the company, for example, to buy more fresh fish and less already frozen fish, decrease the amount of time fish stays frozen etc. Other important fish processing part - washing consumes a great amount of water and is creating the same amount of wastewater (or sometimes even more, because in some parts the water from fish is also going to wastewater). In the first production stages where the fish is being processed to prepare the main product, a considerable amount of waste is created due to the grading, dehulling, destemming/destalking and trimming, cutting, chopping processes. Jayasinghe and Hawboldt analysed that the production of biofuel from oil from fish waste could have environmental and economic benefits, considering that $50 \%$ of the initial fish weight becomes a waste within fish processing [7]. Also, additional energy and resources are needed to manage material handling and storage, sterilization, and other processes that are needed to maintain fish production processes in order.

Table 1 gathers information regarding various processes and stages from fish processing companies that indicates the specific energy consumption, water consumption and created amount of wastewater per tonne of fresh fish. The data was conducted considering the best available technologies (BAT) [5]. 
TABLE 1. BREF DATA FOR FISH PROCESSING COMPANIES [5]

\begin{tabular}{lll}
\hline & $\begin{array}{l}\text { Energy consumption, } \\
\mathrm{kWh} / \mathrm{t} \text { fish }\end{array}$ & $\begin{array}{l}\text { Wastewater, } \\
\mathrm{m}^{3} / \mathrm{t} \text { fish }\end{array}$ \\
\hline Frozen fish thawing & $\mathrm{NI}$ & 5 \\
Grinding & $0.8-1.2$ & 1 \\
White fish filleting & $65-87$ (including ice, freezing and filleting) & $5-11$ \\
Unloading of fish & 3 & $2-5$ \\
Freezing and storage & $10-14$ & $\mathrm{NI}$ \\
Deheading of white fish & $0.3-0.8$ & $\mathrm{NI}$ \\
\hline
\end{tabular}

The main fish processing processes in Latvia are salting, freezing, smoking, producing of non-sterilised and sterilised canned fish food [8]. In 2017 the total fish products were 55400 tonnes, where the highest share of the products was chilled, frozen fish and filleted fish $-20.9 \%$, and canned food from sprats, sardines and sardinella $-15.3 \%$ [9].

The aim of this paper is to understand and evaluate how to increase the efficiency of the fish production process, choosing from several alternatives just one - the least efficient one in the company. It was decided to use method MULTIMOORA as the most suitable for this research and the set goal. In this way the company's efficiency will be improved, therefore achieving the best result with limited resources.

\section{Methodology}

Multi-Objective Optimization on the basis of Ratio Analysis (MULTIMOORA) was used as a research method to evaluate the alternative improvements, considering various parts of the production processes in order to increase the efficiency of fish production companies. The current state of the company that is the main research object requires improvements in the production process, including technologies and management of the resources. However, the company does not have enough financial resources to implement all the necessary improvements at the same time, therefore, the multi-criteria decision making method was used to evaluate which alternative would be the most essential to be improved first in the specific fish production company.

The full version of MULTIMOORA was first introduced in 2010 by Brauers and Zavadskas [10]. This method summarizes MOORA method (including ratio system and reference point), and the full multiplicative form method. This method was chosen to be used in this study in order to obtain the results that are based not only on one approach, but that also considers the results from three distinct approaches. The Fig. 2 shows basic steps needed to obtain the results for the method MULTIMOORA. 


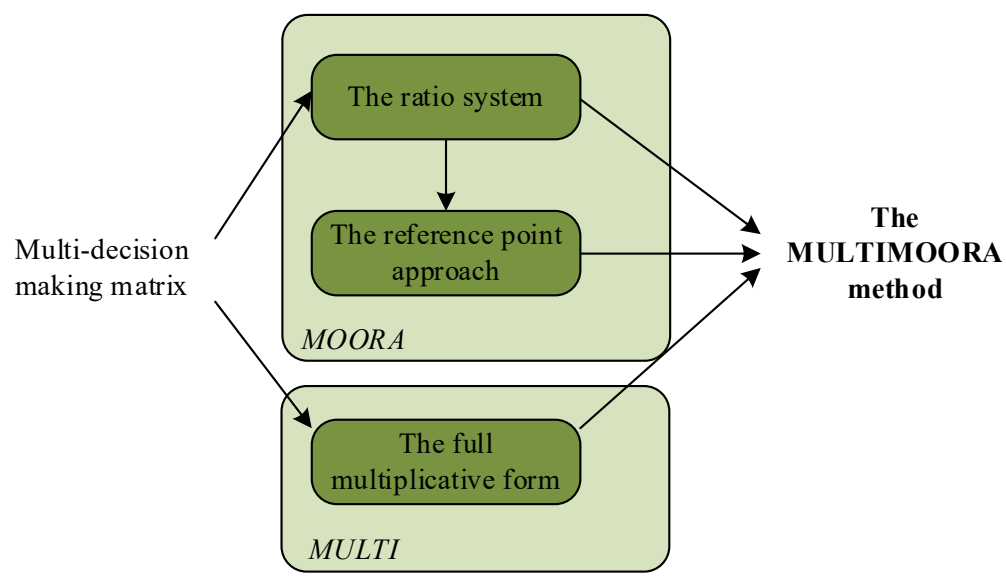

Fig. 2. Steps of MULTIMOORA method [11].

\subsection{Examples of MULTIMOORA Case Study}

MULTIMOORA method is used when the decision needs to be made in favour of one of several alternatives. The method MULTIMOORA was used to evaluate several projects by considering payback time, net present value, internal rate of return and other criteria that needs to be considered before the project implementation. In the initial evaluation, project $\mathrm{A}$ was the best option considering the government income, but project $\mathrm{B}$ - for the increase in employment, and project $\mathrm{C}$ was somewhere in between of both previous alternatives. Therefore, in this case, to understand which alternative is better and which project to implement, method MULTIMOORA was used. As the result of the method, project A was considered to be the best alternative [10].

In the research [11], authors used the method MULTIMOORA to choose the most suitable laptop for the office work where the decision makers were workers themselves. In the result of performed method, the most suitable laptop was chosen, considering the necessary computer parameters needed for the office work [11].

\subsection{MOORA: Ratio System}

The description of the method comes from the authors of the method - Brauers and Zavadskas - when it was introduced to others for the first time, firstly method MOORA [12] in 2006 and MULTIMOORA (MOORA combined with full-multiplicative form) in 2010 [11].

Firstly, the decision-making matrix, where the alternatives and criteria are chosen, the matrix shows the performance of several alternatives with respect to the criteria. The evaluation can be done by using the measurement scales, or actual parameters (for example, cost, lifetime etc.), however, in those cases pairwise comparison is needed [12]. The weights for criteria are neither used in the original, nor in this study in order to decrease the subjections in the evaluation, however, in some cases weight can be added to MULTIMOORA method if necessary [12].

When the decision-making matrix has been done, the further step is to normalize the values of alternatives in the matrix by using Eq. (1): 


$$
x_{i j}^{*}=\frac{x_{i j}}{\sqrt{\sum_{i=1}^{n} x_{i j}^{2}}},
$$

where

$x_{i j}$ - the response of alternative $j$ to objective $i$;

$x_{i j}^{*}$-dimensionless number representing the normalized response of alternative $j$ to objective $i$ (in an interval $[0 ; 1]$ );

$$
\begin{aligned}
& i=1,2, \ldots, \mathrm{n} ; \\
& j=1,2, \ldots, \mathrm{m} .
\end{aligned}
$$

Next, the optimization needs to be performed. For this case, the criteria are divided into two groups: beneficial (criteria that need to be maximized) and non-beneficial (criteria that need to be minimized). Then, the sum of non-beneficial parameters is subtracted from the sum of beneficial parameters as shown in Eq. (2):

$$
y_{j}^{*}=\sum_{i=1}^{i=g} x_{i j}^{*}-\sum_{i=g+1}^{i=n} x_{i j}^{*},
$$

where

$i=1,2, \ldots, g-$ the objectives to be maximized;

$i=g+1, g+2, \ldots, n-$ the objectives to be minimized;

$y_{j}^{*}$ - normalized assessment of alternative $\mathrm{j}$ with respect to all objectives.

Then the sum for each alternative is calculated and an ordinal ranking in ascending order of the $y_{j}{ }^{*}$ shows the final preference of this method, achieving the final evaluation of the first method.

\subsection{MOORA: Reference Point Theory}

The second part of Moora is called the Reference Point Theory. This method starts with already normalized values that have been obtained from Eq. (1). Next step involves finding the maximal value for each criterion, and then subtract each value from the maximal value as shown by Eq. (3):

$$
\min _{(j)}\left\{\max _{(i)}\left|r_{i}-x_{i j}^{*}\right|\right\},
$$

where $r_{i}$ is the $i^{\text {th }}$ co-ordinate of the maximal objective reference point.

Again, the ordinary ranking is done, however in this case - in descending order. This is the final step to be performed of MOORA method, achieving the results of the second method.

\subsection{Full-Multiplicative Form}

Full-multiplicative form is the third and the last method performed in MULTIMOORA. This method uses the decision-making matrix that is made by decision makers in the beginning. To achieve utility of alternative, this method considers beneficial and non-beneficial criteria; therefore, non-beneficial criterion is used as denominators as seen in Eq. (4): 


$$
U_{j}^{\prime}=\frac{\prod_{g=1}^{i} x_{g i}}{\prod_{k=i+1}^{n} x_{k j}},
$$

where

$i$ - number of objectives to be maximized;

$n$ - number of objectives to be minimized;

$U_{j}^{\prime}-$ utility of alternative $\mathrm{j}$ with objectives to be maximized and objectives to be minimized.

Then the ranking of alternatives is done in ascending order based on the results of Eq. (4). This is the last step to be performed to obtain the missing ranking of MULTIMOORA method.

\subsection{MULTIMOORA}

MULTIMOORA considers results from all three methods - ratio system, reference point theory and full-multiplicative form. Each of the method as a result achieves ranking that is finally combined together to achieve the final ranking - the ranking of MULTIMOORA.

\subsection{Case Study}

A specific fish processing plant data was used to perform MULTIMOORA method in order to evaluate the efficiency of current processing processes. Knowing the fact that the production plant is too large and too much investments would be needed to improve everything; the first improvements are needed where the efficiency is the lowest. Therefore, the method MULTIMOORA is used to conduct the least efficient process of this specific production plant.

The evaluation was done for two production stages (alternatives) based on the division mentioned in BAT document (see Fig. 3):

- Preliminary processing;

- Preservation methods.

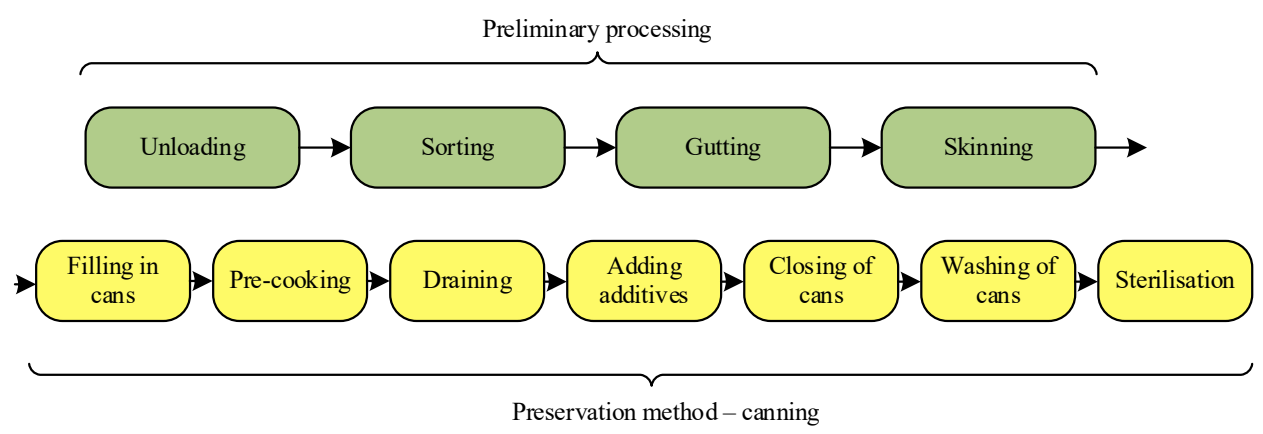

Fig. 3. Fish production stages.

As discussed before, the fish processing plant uses a high volume of resources and contributes to global environmental problems by consuming energy, water and producing wastewater and waste - all these indicators are used as objectives in the evaluation.

Two alternatives have been chosen for the research in respect to four indicators. The measurement units used for the indicators are collected and calculated per $1000 \mathrm{~kg}$ fresh 
fish (see Table 2). The data shown in Table 1 is also the first step of MULTIMOORA decision-making matrix.

TABle 2. Case Study Data - Decision-Making MatriX

\begin{tabular}{lllll}
\hline & $\begin{array}{l}\text { Energy consumption, } \\
\mathrm{kWh} / \mathrm{t}_{\text {fish }}\end{array}$ & $\begin{array}{l}\text { Wastewater, } \\
\mathrm{m}^{3} / \mathrm{t}_{\text {fish }}\end{array}$ & $\begin{array}{l}\text { Water, } \\
\mathrm{m}^{3} / \mathrm{t}_{\text {fish }}\end{array}$ & $\begin{array}{l}\text { Waste, } \\
\mathrm{kg} / \mathrm{t}_{\text {fish }}\end{array}$ \\
\hline Preliminary processing & 4.06 & 15.97 & 15.97 & 314.92 \\
Preservation methods & 133.28 & 2.77 & 2.77 & 24.73 \\
\hline
\end{tabular}

The particular alternatives (preliminary processing and preservation methods) where chosen based on the production processes stages. In this production plant, the improvements are needed in order to increase the efficiency of the company, however, based on the data, neither of the criteria seem to be standing out. For example, in preliminary processing the consumption of water and wastewater amount, and waste is a lot higher than in preservation methods, however, in the other case the consumption of energy is very high.

In this case, to gain the knowledge which of two alternatives has the lowest efficiency and therefore needs to be improved first, multi-criteria decision making methods can be used, more specifically - MULTIMOORA method is used on this research.

\section{RESUlts}

Table 2 shows the necessary input data for MULTIMOORA method, the first step is to calculate the ratio system. The first part of the calculation steps is seen in Table 3, where the squares, the sum of the squares and their square roots are being calculated.

TABLE 3. RATIO SYSTEM - PART 1

\begin{tabular}{llllll}
\hline & & Energy consumption & Wastewater & Water & Waste \\
\hline \multirow{2}{*}{ Square } & Preliminary processing & 16.4836 & 255.0409 & 255.0409 & 99174.6064 \\
& Preservation methods & 82277.1856 & 8.7616 & 7.6729 & 14970.0061 \\
Sum & & 41354.98 & 82293.67 & 263.80 & 262.71 \\
Root & 203.36 & 286.87 & 16.24 & 16.21 \\
\hline
\end{tabular}

Table 4 shows the second part of the Ratio system method, where the objectives are divided by their square roots (described in the Eq. (1)). Then, the sum of each alternative in respect to all criteria are being calculated. Based on the results of the sum, the ranking is done in descending order.

TABLE 4. RATIO SYSTEM - PART 2

\begin{tabular}{lllllll}
\hline & Energy consumption & Wastewater & Water & Waste & Sum & Rank \\
\hline Preliminary processing & 0.01 & 0.98 & 0.99 & 0.93 & 2.91 & 1 \\
Preservation methods & 1.00 & 0.18 & 0.17 & 0.36 & 1.72 & 2 \\
\hline
\end{tabular}

The second part of MOORA method is to calculate the reference point. First, the maximal value of each criterion is conducted, and then, by using Eq. (3), the deviation from the maximal value is calculated. Then, the maximal value of calculated values of the alternatives 
are found. The last step to perform is to rank the achieved results in the ascending order (Table 5).

TABLE 5. THE REFERENCE POINT PART OF MOORA

\begin{tabular}{llllllll}
\hline Max value & & 1.00 & 0.98 & 0.99 & 0.93 & 1.00 & 0.98 \\
\hline $\begin{array}{l}\text { Deviation from the } \\
\text { reference point }\end{array}$ & Preliminary processing & 0.99 & 0.00 & 0.00 & 0.00 & 0.99 & 0.00 \\
& Preservation methods & 0.00 & 0.80 & 0.81 & 0.57 & 0.00 & 0.80 \\
\hline
\end{tabular}

To achieve the results for the full multiplicative form, Eq. (6) is used. In this case, all indicators are non-beneficial and need to be minimized, however, there are no criteria to be maximized, this is why all the criteria are used as multipliers in Eq. (6), but not as denominators. In Table 6, the last column shows the ranking based on the results conducted from the final results - penultimate column.

TABLE 6. THE Full MULTIPLICATIVE FoRM

\begin{tabular}{lllllllll}
\hline & 1 & 2 & 3 & 4 & 5 & 6 & 7 & 8 \\
& $\begin{array}{l}\text { Energy } \\
\text { consumption }\end{array}$ & Wastewater & $3=1 \cdot 2$ & Water & $5=3 \cdot 4$ & Waste & $7=5 \cdot 6$ & Rank \\
\hline $\begin{array}{l}\text { Preliminary } \\
\text { processing }\end{array}$ & 4.06 & 15.97 & 64.84 & 15.97 & 1035.47 & 314.92 & 4.06 & 1 \\
$\begin{array}{l}\text { Preservation } \\
\text { methods }\end{array}$ & 286.84 & 2.96 & 849.05 & 2.77 & 2351.86 & 122.35 & 286.84 & 2 \\
\hline
\end{tabular}

Finally, all the three methods and all the results have been covered, as well the final result of MULTIMOORA method can be seen in Fig. 4 - the score shows efficiency, therefore, the higher the score is, the higher the efficiency in the specific product part is compared to the processes in the production company.

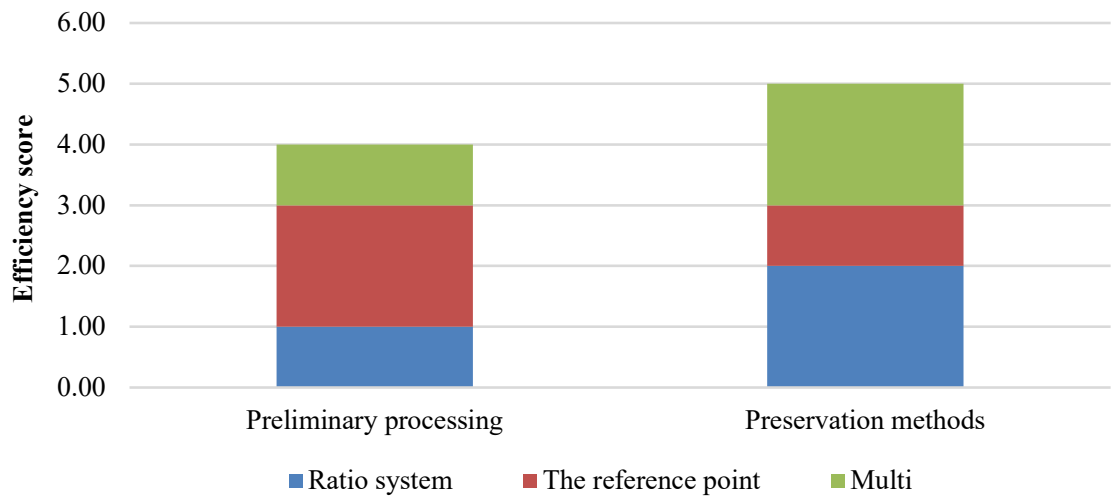

Fig. 4. The results of MULTIMOORA method.

The results showed that between two fish production stages namely preliminary processing that includes the processing of fish to prepare it to make a specific product and preservation method where the product is made (in this case - canning), the least efficient alternative is preliminary processing, although the second alternative has been evaluated one slightly higher. 


\section{Discussion}

The results have shown that the process where the fish is preliminary processed needs to be improved to achieve the best efficiency improvements. This stage of production includes the following processes: unloading, sorting, gutting, and skinning.

Based on the results of MULTIMOORA method, the improvements for specific production stage have been defined, and they are as follows:

- To use water in a more efficient way, nozzles and solenoid shut-off valve can be installed, therefore, decreasing the water consumption by $50 \%$;

- Wastewater can be reused for the floor washing;

- The large amount of waste is being created in this stage, and even though it is impossible to avoid the waste, it can be used in a more useful way. One of the possibilities is to ferment it and then use as animal feed. Production of fish flour is another possible option. In this way waste is no longer waste but a resource that can be used for useful and high value added products;

- Based on the suggestions mentioned in BAT document, the improvements for this stage is to reduce the total amount of waste, the separation of residues can be used. Due to this method, the consumption of water is reduced (European Commission, 2018).

It also needs to be considered that while improving processes in one stage, the efficiency in other processes may also increase, for example, if the wastewater that does not contain any chemicals is reused for washing, then the water will be collected also from the wastewater that is created during preservation method performance, reducing the amount of total consumed water for cleaning due to the reused water from both production stages.

\section{Conclusions}

The method MULTIMOORA was used to evaluate two production stages at a specific fish processing company. The aim of the method was to find which of the two alternatives is the most inefficient and should be improved first to gain the highest improvement in the efficiency of the company, considering that most companies to not have enough financial resources to improve the efficiency in all the inefficient places.

The results showed that the process where the fish is preliminary processed is the most inefficient in the production. Within this process, the high amount of waste is produced, as well as the consumed water and the produced amount of wastewater is high, therefore four suggestions were made based on BAT and researchers of this paper.

The method MULTIMOORA can also be used to evaluate efficiency and compare various fish preservation methods such as salting, smoking, and drying in order to make improvements where they are needed the most. The method can be used to compare the results from different fish processing companies that may use similar processing and preservation methods and to compare results, therefore finding possible improvements, where the indicators of resources are higher than they are for another company.

\section{ACKNOWLEDGEMENT}

This research is funded by European Maritime and Fisheries Fund, project "Improving production efficiency in the fish processing companies". 


\section{REFERENCES}

[1] Food and Agriculture Organization of the United Nations. The state of the world fisheries and aquaculture. [Online] [Accessed: 20.11.2019]. Available: http://www.fao.org/state-of-fisheries-aquaculture

[2] European Commission. Fisheries. [Online] [Accessed: 02.12.2019]. Available: https://ec.europa.eu/fisheries/6-consumption_en

[3] Eurostat. Statistical books. The EU in the world. 2018 edition.

[4] Terehovics E., Veidenbergs I., Blumberga D. Analysis of Operation Parameters of Fish Refrigeration by Exergy Analysis. Case Study. Environmental and Climate Technologies 2019:23(1):229-241. https://doi.org/10.2478/rtuect-2019-0015

[5] European Commission. Integrated Pollution Prevention and Control. Reference Document on Best Available Techniques in the Food, Drink and Milk Industries. Final draft, 2018. https://doi.org/10.2760/243911

[6] Terehovics E., Veidenbergs I., Blumberga D. Parameters that Affect Electricity Consumption in Fish Freezing. Case Study. Environmental and Climate Technologies 2019:23(3):15-25. https://doi.org/10.2478/rtuect-2019-0076

[7] Jayasinghe P., Hawboldt K. A review of bio-oils from waste biomass: Focus on fish processing waste. Renewable and Sustainable Energy Reviews 2012:16(1):798-821. https://doi.org/10.1016/j.rser.2011.09.005

[8] Ministry of Agriculture Republic of Latvia. Fishing sector in Latvia. [Online] [Accessed: 18.12.2019]. Available: https://www.zm.gov.lv/zivsaimnieciba/statiskas-lapas/zivju-apstrade/apstrade?nid=744\#jump (in Latvian)

[9] Ministry of Agriculture Republic of Latvia. Sales of fish products. [Online] [Accessed: 18.12.2019]. Available: https://www.zm.gov.lv/zivsaimnieciba/statiskas-lapas/zivju-apstrade/sarazotas-zivju-produkcijasrealizacija?nid=745\#jumpb (in Latvian)

[10] Brauers W. K. M., Zavadskas E. K. Project management by MULTIMOORA as an instrument for transition economies. Technological and Economic Development of Economy 2010:16(1):5-24. https://doi.org/10.3846/tede.2010.01

[11] Adalı E. A., Işık A. T. The multi-objective decision making methods based on MULTIMOORA and MOOSRA for the laptop selection problem. Journal of Industrial Engineering International 2017:13(2):229-237. https://doi.org/10.1007/s40092-016-0175-5

[12] Brauers W. K., Zavadskas E. K. The MOORA method and its application to privatization in a transition economy. Control and Cybernetics 2006:35:445-469. 